AperTO - Archivio Istituzionale Open Access dell'Università di Torino

\title{
Mechanism-based therapeutic approaches to cachexia
}

\section{This is the author's manuscript}

Original Citation:

Availability:

This version is available http://hdl.handle.net/2318/140141

since 2016-08-02T16:35:51Z

Published version:

DOI:10.1016/B978-0-12-410473-0.00011-8

Terms of use:

Open Access

Anyone can freely access the full text of works made available as "Open Access". Works made available under a Creative Commons license can be used according to the terms and conditions of said license. Use of all other works requires consent of the right holder (author or publisher) if not exempted from copyright protection by the applicable law. 
This is the author's final version of the contribution published as:

F. Penna; G. Bonelli; F.M. Baccino; P. Costelli. Mechanism-based therapeutic approaches to cachexia. VITAMINS AND HORMONES. 92 pp: 271-299. DOI: 10.1016/B978-0-12-410473-0.00011-8

The publisher's version is available at:

http://linkinghub.elsevier.com/retrieve/pii/B9780124104730000118

When citing, please refer to the published version.

Link to this full text:

http://hdl.handle.net/2318/140141 
MECHANISM-BASED THERAPEUTIC APPROACHES TO CACHEXIA

F. Penna, G. Bonelli, F.M. Baccino, P. Costelli

Department of Experimental Medicine and Oncology, University of Torino, Italy

Running title: Treatments for cachexia

Corresponding author: Paola Costelli

Department of Experimental Medicine and Oncology

University of Torino

Corso Raffaello 30, 10125 Torino, Italy

Tel: +39-011-6707062; Fax +39-011-6707753

e-mail: paola.costelli@unito.it 


\section{Abstract}

Cachexia is a multifactorial syndrome characterized by body weight loss, depletion of adipose tissue and skeletal muscle mass, and marked alterations of the metabolic homeostasis. The occurrence of cachexia significantly impinges on patient's morbidity and mortality, and on quality of life. Inflammation, anorexia/malnutrition, alterations of protein and lipid metabolism are among the main mechanisms involved in the development of cachexia. While anorexia and malnutrition are long known contributing factors, the mechanisms leading to inflammation and metabolic alterations were clarified later on. On these premises, several therapeutic approaches were proposed. Most of them are in the pre-clinical phase, but some already reached the clinical experimentation. The present review will focus on treatment options proposed on the basis of mechanistic alterations. In this regard, in addition to nutritional and anti-inflammatory strategies, also approaches based on perturbation of specific signal transduction pathways are taken into consideration.

Key words: cachexia, inflammation, cytokines, signal transduction, anorexia, muscle wasting, adipose tissue depletion, protein turnover, lipolysis 


\section{Introduction}

Chronic pathologies such as diabetes, cancer, congestive heart failure, autoimmune or neurological diseases, result in a significant impairment of patients' quality of life. Indeed, in addition to features specific to each disease, patients frequently show marked alterations of whole body homeostasis, that ultimately result in tissue wasting, impaired nutritional status and reduced ability to perform daily activities. This condition, termed as cachexia, is often disregarded until it becomes clinically evident. Unfortunately, at this point it is also barely responsive to the few treatments available, most of which, however, are merely symptomatic. In this regard, early targeted interventions have been proposed to be helpful in preventing the progression of cachexia form a 'latent' to an 'overt' condition. Indeed, once a sort of no-return point is reached, the balance among several components contributing to disease-induced derangement is likely to get lost, and no intervention can be successful anymore. These observations put in evidence the urgent need of biomarkers suitable to detect the condition of 'latent' cachexia.

Few years ago a couple of papers reported a definition of cachexia (Evans et al., 2008; Muscaritoli et al., 2010): 'Cachexia may be defined as a multifactorial syndrome characterized by severe body weight, fat and muscle loss and increased protein catabolism due to underlying disease(s). Cachexia is clinically relevant since it increases patients' morbidity and mortality. Contributory factors to the onset of cachexia are anorexia and metabolic alterations, i.e. increased inflammatory status, increased muscle proteolysis, impaired carbohydrate, protein and lipid metabolism' (quoted from Muscaritoli et al., 2010). Such efforts in defining cachexia are particularly relevant especially in view of identifying populations of patients in which the syndrome is more likely to develop. In this regard, a three stage classification of cachexia has been recently proposed: precachexia, cachexia, and refractory cachexia (Fearon et al., 2011). Due to the complex etiology of this syndrome, the assessment of cachexia should include several parameters, such as the occurrence of anorexia and malnutrition, the loss of body weight, the depletion of adipose tissue, the loss of muscle mass and strength, the activation of 
hypercatabolism, the presence of a chronic inflammatory state, and last, but not least, the impact that cachexia exerts on the patient.

\section{Body and tissue wasting}

The loss of body weight is one of the hallmarks of cachexia. While its pathogenesis may be different, going from simple caloric restriction to the profound derangements observed in cancer patients, its occurrence often associates with worse prognosis and poor tolerance to therapies. This is particularly evident in cancer patients, where weight loss has been reported in about $50 \%$ to $70 \%$ of new diagnosis (Muscaritoli et al., 2006). Neoplastic patients presenting with weight loss before the beginning of treatments often show poor tolerance to surgery, chemotherapy, and radiotherapy. By contrast, a good performance status positively correlates with tolerance and response rates to chemotherapy and radiotherapy, and with survival (Tan and Fearon, 2008). In this regard, particular attention should be given to patients in which body weight loss could be masked, such as those presenting with water retention (cancer, liver chirrhosis, heart or renal failure), or obesity.

Body weight loss mainly results from reduced adipose tissue and/or skeletal muscle mass. This latter should be regarded as the main feature of ongoing cachexia, for the following reasons: firstly, muscle mass below $50 \%$ of body weight is not compatible with survival (Wolfe, 2006, and references therein), and, secondly, the adipose tissue may not be affected early, at least in neoplastic patients. Consistently, obese cancer patients frequently show significant muscle depletion in face of elevated body mass index and maintenance of adipose tissue mass (sarcopenic obesity; Prado et al., 2008; Stenholm et al., 2008). Not only, the increase in fat in obese subjects masks the occurrence of lean body mass, in particular in the early stages of the disease, thus delaying the adoption of specific metabolic interventions. The different kinetic of depletion in muscle and fat, however, should not divert the attention from the latter. Indeed, many years ago Argilés and coworkers (2005) proposed the existence of a cross talk between the two tissue compartments. Such hypothesis has been clearly demonstrated in a recent report (Das et 
al., 2011), showing that inhibition of lipolysis in tumor-bearing mice by genetic ablation of lipolytic enzymes prevents hyperlipidemia and adipose mass depletion, but also skeletal muscle wasting. Irrespective of the underlying disease, the skeletal muscle, which accounts for approximately half of the body protein mass, is severely affected in cachexia. Skeletal muscle is a very heterogeneous tissue, in charge of several biological functions such as movement, stability, heat production and cold tolerance. Considered in the past as a mere protein reservoir, it is now recognized to release cytokines and other humoral factors (Pedersen \& Febbraio, 2008). Since the skeletal muscle plays a pivotal role in the overall energy balance, regulating lipid flux, plasma glucose storage, and insulin sensitivity, it participates in the control of whole body metabolism, also acting in concert with the adipose tissue. The main factor regulating skeletal muscle mass is protein content, that strictly depends on the balance between synthesis and degradation rates. Physiologically, in the adult individual protein synthesis does not exceed degradation, and viceversa, allowing the maintenance of the skeletal muscle mass. Generally speaking, modulations of both sides of turnover eventually converge to produce a new steady-state. In this regard, enhanced protein synthesis, which responds earlier than degradation to the inducing stimuli, mainly results in muscle hypertrophy, while protein hypercatabolism leads to muscle depletion.

\section{Anorexia}

Defined as reduced desire to eat and early satiety, anorexia leads to decreased number of meals during the day and reduced amount of food consumed in each meal. It is a frequent feature of chronic pathologies, although it is often not recognized and left untreated, thus significantly contributing to malnutrition. In this regard, food intake in patients should be accurately and routinely monitored, in order to immediately identify a change from the usual habit. At least in cancer patients, tools such as the Functional Assessment of Anorexia/Cachexia Therapy and the North Central Cancer Treatment Group Anorexia/Cachexia can provide a qualitative and quantitative assessment of anorexia (Muscaritoli et al., 2010). 
In addition to alterations in the central control of eating, secondary causes of reduced food intake may be constipation, stomatitis, pain and depression. From a therapeutic point of view, the mechanisms underlying anorexia in the different patients should be readily identified, in order to adopt the most correct approach. To recognize the occurrence of anorexia may be relevant also in view of the fact that early satiety correlates with worse outcome, at least in cancer patients (Walsh et al., 2002).

The altered control of eating behavior mainly depends on pro-inflammatory cytokines (TNFa, IL-6 and IL-1). Such mediators, directly, or indirectly through modulations of the physiological levels of several neuropeptides (leptin, neuropeptide $\mathrm{Y}$, melanocortin, agouti-related peptides), modify appetite and metabolic rate. More specifically, cytokine bioactivity results in induction of anorexigenic pathways and inhibition of the orexigenic ones, leading to appetite loss and increased satiety (Grossberg et al., 2010).

The occurrence of anorexia may contribute to explain the loss of body weight that characterizes patients affected by chronic diseases. However, at least in cancer cachexia, weight loss generally differs from that due to simple food deprivation. During caloric restriction, indeed, initially glucose and aminoacids are mobilized from the liver, fat becoming the primary energy source later on, in order to preserve tissue protein. By contrast, patients with cancer cachexia fail to turn metabolism into a protein-sparing setting, resulting in a persistently negative nitrogen balance which defies a purely nutritional correction (Laviano et al., 2003, Lancet Oncol).

\section{Inflammation}

Inflammation is a tightly regulated mechanism aimed at protecting the organism against alterations of the homeostasis due to different stimuli such as biological, physical or chemical agents on one side, and damaged, infected, or neoplastic cells on the other. The inflammatory response is generally endowed with self-regulation properties, achieved through a complex network including both inflammatory/immune cells and humoral mediators, that regulates the equilibrium between pro-inflammatory and anti-inflammatory stimuli. When the balance between 
pro- and anti-inflammatory response is persistently lost, chronic inflammation occurs. This was suggested to significantly contribute to the pathogenesis of several chronic illnesses such as autoimmune and neurodegenerative diseases, diabetes and its complications, cancer, AIDS, obesity. In this regard, all these pathological states are associated with increased circulating levels of pro-inflammatory mediators. As an example, IL-6, TNF $\alpha$ and TNF soluble receptors are detectable in patients affected by chronic heart or renal failure (Li et al., 2011; Niewczas et al., 2012). In these latter, increased levels of acute phase reactants correlate with increased mortality (Noori et al., 2011). Similarly, pro-inflammatory cytokines such as TNF $\alpha$, IL-6, $\gamma$-INF, LIF are increased also in cachectic neoplastic patients (reviewed by Seruga et al., 2008).

The link between cancer and inflammation was proposed by Virchow already in the $19^{\text {th }}$ century (the Virchow hypothesis; Durham et al., 2009), and again after the discovery of the first cytokines (see Winfield et al., 2008). In 1972 Prehn demonstrated that immune cells in tumor stroma, such as M2 macrophages, Treg lymphocytes, dendritic cells, promote tumor growth. Indeed, inflammation plays a dual role: it is involved in carcinogenesis and tumor progression, but also in the metabolic derangements induced in the patient by the presence of the tumor. Recently, the relation between the acute phase response (systemic inflammation) and cancer cachexia was proposed from the observation that enhanced liver protein synthesis could drive muscle protein hypercatabolism contributing to the elevated resting energy expenditure (Durham et al., 2009). Not only, the skeletal muscle itself was proposed as a source of acute phase reactants, likely diverting aminoacids from the synthesis of structural proteins to that of acute phase mediators (Bonetto et al., 2011). Of interest, acute phase proteins are further increased by nutritional supplementation, suggesting that anti-inflammatory treatments should be included in the therapeutic protocol (Stephens et al., 2008). Systemic inflammation appears correlated with reduced survival. Indeed, cancer patients with high CRP levels survive less than those with low/normal levels (Stephens et al., 2008). In some studies survival is more accurately predicted by CRP levels than by tumor stage (Stephens et al., 2008). In this regard, CRP is used to provide scores suitable for the clinical use, such as the Glasgow prognostic score that couples increased CRP ( $\geq 10 \mathrm{mg} / \mathrm{l})$ and 
hypoalbuminemia ( $\leq 35 \mathrm{mg} / \mathrm{l})$; CRP and white blood cells; CRP $(\geq 10 \mathrm{mg} / \mathrm{l})$, body weight loss $(\geq$ $10 \%$ ), reduced food intake ( $\leq 1500 \mathrm{kcal} /$ day; Fearon et al., 2006).

Another good example of inflammation-driven disease is diabetes. Hyperglycemia, indeed, leads to the production and accumulation of advanced glycation end-products (AGE), known to induce inflammatory reactions. AGE accumulation leads to oxidative stress increasing the risk of diabetes complications such as hypertension, neuropathy, nephropathy and retinopathy, as well as the risk of cancer development (Nienhuis et al., 2009). In addition, at least type II diabetes is frequently associated with obesity, another pro-inflammatory condition (de Heredia et al., 2012).

In the last years, several signaling pathways, directly or indirectly activated by proinflammatory cytokines, were proposed to contribute to the development of cachexia, with particular reference to those involved in causing anorexia (see above), lipid depletion, and skeletal muscle wasting.

Pro-inflammatory cytokines, together with altered production/release of classical hormones and/or growth factors, result in a complex network that exerts an inhibitory action on anabolic and/or anticatabolic signals, in favor of lipolysis and proteolysis. As an example, muscle wasting, increased ubiquitin expression and proteasome enzymatic activity are induced in healthy animals by administration of TNF $\alpha$ or IL-1 (reviewed in Tisdale, 2008). Consistently, at least in cancer cachexia, many years ago few studies demonstrated the crucial role played by cytokines in the onset of muscle wasting, showing that loss of muscle mass, protein hypercatabolism and ubiquitin hyperexpression could be prevented by treatment of tumor-bearing animals with antibodies directed against IL-6, TNF $\alpha$, or IFN $\gamma$ (Matthys et al., 1991; Costelli et al., 1993; Strassmann et al., 1993). Altered cytokine homeostasis, positively correlated with disease progression and mortality rates, was reported also in cancer patients (Attard-Montalto et al., 1998; Nakashima et al., 1998). Cancer cachexia apart, pro-inflammatory cytokines contribute to muscle wasting also in other chronic diseases such as sepsis or AIDS, as well as in aging (see Späte and Schulze, 2004).

Pro-inflammatory mediators are likely involved also in pathological states where muscle depletion results from the coexistence of protein hypercatabolism and impaired activation of the 
regenerative response. In this regard, TNF $\alpha$, was shown to impinge on myogenesis with opposite outcomes: increased circulating levels appear to inhibit myogenesis (Guttridge et al. 2000; Coletti et al. 2002; 2005), while high local concentrations promote regeneration in injured muscles (Chen et al. 2005). Reduced stem cell recruitment may contribute to impaired myogenesis (Nicolas et al., 2005), and TNF $\alpha$ was proposed to abrogate satellite cell function, resulting in delayed or impaired muscle regeneration in mice after injury (Moresi et al., 2008). Recently, a TNF $\alpha$-dependent, p38 $\alpha$ regulated epigenetic control of Pax7 expession was identified, directly linking TNF $\alpha$ action to the inhibition of satellite cell proliferation (Palacios et al., 2010).

In addition to protein turnover, several cytokines significantly affect lipid metabolism. TNF $\alpha$, IL-6, LIF and $\gamma$-INF are known to down-regulate lipoprotein lipase (LPL) activity, thus reducing triglyceride storage in adipose tissue, resulting in hyperlipidemia. TNF $\alpha$, in particolar, interferes with the synthesis of adipocyte lipogenic enzymes and stimulates triglyceride degradation by activating the hormone-sensitive lipase (HSL; van de Woestijne et al., 2011). The relevance of these enzymes to the genesis of tissue depletion, at least in cancer cachexia, was recently demonstrated by Das and coworkers (2011), showing that tumor growth in mice null for the adipose triglyceride lipase (ATGL) or HSL fails to induce both adipose tissue and skeletal muscle wasting. In contrast with the effects exerted on the adipose tissue, TNF $\alpha$ increases hepatic lipogenesis, contributing to the hyperlipidemia that characterizes cachexia (van de Woestijne et al., 2011).

Finally, the adipose tissue itself produces and releases a huge number of cytokines, termed adipokines; they are involved in several physiological processes, including the regulation of lipid metabolism, and were shown to play a role also in the pathogenesis of several diseases (Trayhurn and Wood, 2004). Among adipokines, leptin and adiponectin deserve particular attention. The former, produced and secreted proportionally to the adipose tissue mass, interferes with the regulation of both food intake and energy consumption, by acting on the central control of eating (Shan and Yeo, 2011). Physiologically, leptin levels are low and increase in the fasted or fed state, 
respectively. Other factors, such as inflammation and the mediators involved, may impinge on this regulation; in particular, leptin synthesis is increased during acute responses, while decreased in chronic inflammation (Popa et al., 2005). Of interest, leptin itself may act as a pro-inflammatory cytokine (Lago et al., 2007). As for adiponectin, it is known to potentiate fatty acid oxidation and to reduce liver gluconeogenesis, and appears to correlate with body mass index and insulin resistance (Lago et al., 2007). In this regard, adiponectin appears to play a role in the protection against excess adipose tissue deposition, but also in other pathological states characterized by an inflammatory component. Consistently, adiponectin secretion is inhibited by pro-inflammatory cytokines (Bruun et al., 2003). At least in cancer cachexia, however, the involvement of adipokines appears unlikely. Indeed, leptin plasma levels and expression in the adipose tissue were reported to decrease in tumor-bearing animals even in the absence of fat depletion and anorexia (LopezSoriano et al., 1999). Similarly, in gastric cancer patients neither fat loss nor anorexia seem to be regulated by leptin (Wallace et al., 1998). Such observations have been confirmed by recent evidences showing the lack of correlation between adipokines and markers of inflammation such as CRP and IL-6 in patients with non small cell lung cancer (Gulen et al., 2012). However, a different view is reported by Kerem and coworkers (2008).

\section{Tissue wasting in cachexia: hypoanabolism or hypercatabolism?}

The reduction of both adipose tissue and skeletal muscle mass may depend on reduced deposition, increased mobilization, or both. In other words, this means that increased rates of lipid/protein degradation, reduced rates of synthesis or both are responsible for the changes in tissue mass that characterize cachexia in chronic diseases. Increased lipolysis and enhanced protein breakdown are generally accepted as hallmarks of cachexia. However, the possible role played by a condition of hypoanabolism is less clear. In this regard, for example, muscle protein synthesis rates were reported to be reduced, unaltered, or even enhanced in cancer patients (see Pisters and Pearlstone, 1993). 
Increased lipid mobilization was shown to play a central role in adipose tissue depletion associated with cachexia. As an example, high rates of lipolysis (glycerol and free fatty acid turnover, lipid oxidation), also in the presence of hyperglycemia, occur in cachectic cancer patients (Sakurai and Klein, 1998; Korber et al., 1999). In this regard, both expression and activity levels of two lipases (HSL and ATGL) are increased in experimental and human cancer cachexia (Agustsonn et al., 2007). In cancer patients, in particular, lipase expression is inversely correlated with body mass index (see Bing, 2011). Finally, genetic manipulations aimed at deleting each of the two lipases result in restoration of normal adipose tissue mass in tumor-bearing mice (Das et al., 2011; see above). Lipolysis-derived fatty acids, through the action of the adipocyte-specific gene cell death-inducing DNA fragmentation factor-[alpha]-like effector A (CIDEA), may serve as substrates for energy production through oxidation (Laurencikiene et al., 2008).

On the other side, the role played by impaired adipogenesis in cachexia is still to be determined. Generally speaking, the occurrence of reduced lipogenesis is generally inferred by the observation that the activity of LPL is often inhibited in cachexia (Nara-Ashizawa et al., 2001). Similarly, reduced expression of the fatty acid synthase, an enzyme that plays a crucial role in de novo lipogenesis, was reported in rats with adjuvant-induced arthritis, in the absence of increased lipolysis (Martin et al., 2008).

As for protein metabolism, intracellular proteolysis in the skeletal muscle is operated by several systems (see Bonetto, Penna et al., 2009). The autophagic-lysosomal and the proteasomal ones are able to degrade proteins into amino acids or small peptides. By contrast, both the $\mathrm{Ca}^{2+}-$ dependent and the caspase pathways, characterized by a restricted catabolic specificity, only lead to a limited proteolysis of their substrates. As reported above, several pro-inflammatory cytokines were proposed to mediate the induction of protein hypercatabolism. On the other side, anabolism is regulated by a complex interplay among amino acids and hormones/growth factors such as insulin and IGF-1. In this regard, amino acids, in addition to be necessary for the synthesis of new proteins, were shown to interfere with the regulation of mRNA translation (Kadowaki \& Kanazawa, 2003). The stimulation of protein synthesis by anabolic signals such as insulin or IGF-1 results 
from a transduction pathway involving several kinases such as Akt, phosphoinositide-3-kinase (PI3K), glycogen synthase kinase (GSK)-3ß, mammalian Target Of Rapamycin (mTOR), and p70

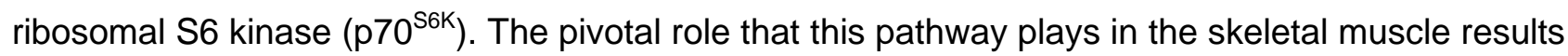
clear from observations showing that experimental conditions aimed at enhancing Akt activity, in cultured myocytes or in the whole muscle, lead to a hypertrophic phenotype (Rommel et al., 2001; Lai et al., 2004). The other way round, inhibition of this pathway was reported in conditions characterized by muscle wasting such as denervation, aging, disuse, or glucocorticoid treatment, and its restoration by means of IGF-1 administration or IGF-1 local hyperexpression is able to prevent or correct muscle depletion (reviewed in Glass, 2010). An exception, in this regard, is experimental cancer cachexia, where the PI3K/Akt/mTOR pathway is not down-regulated (Acharrya et al., 2005; Penna, Bonetto et al., 2010), and muscle atrophy cannot be prevented by both IGF-1 administration or its hyperexpression in the skeletal muscle (Costelli et al., 2006; Penna, Bonetto et al., 2010).

On the whole, the observations reported above could support the concept that, cancer cachexia apart, hypoanabolism is a relevant factor contributing to muscle depletion. However, besides inducing protein synthesis, the PI3K/Akt signaling pathway also down-regulates protein catabolism by maintaining in the inactive conformation transcription factors of the FoxO family. FoxO3, in particular, regulates both the expression of molecules involved in proteasomal degradation, namely the muscle-specific ubiquitin ligase atrogin-1 (Sandri et al., 2004; Stitt et al., 2004), and the lipidation of LC3, an essential actor in the autophagic-lysosomal proteolysis (Zhao et al., 2007). Consistently, FoxO3 deletion results in the protection against muscle wasting in experimental models of fasting and denervation atrophy (Zhao et al., 2007).

Taking these considerations into account, the question remains opened: is hypoanabolism a crucial actor in muscle wasting, or is it just a 'side-effect' of the marked hypercatabolic state? The question is still more compelling for adipose tissue depletion, since most of the studies address the lipolytic side of metabolism, without taking into account the anabolic processes. 


\section{From mechanistic alterations to therapeutic strategies}

Studies performed on different experimental models have begun to unravel the causative factors and the pathophysiological perturbations that underlie cachexia, providing information useful to devise novel antagonist tools. The vast majority of the research in the field of new therapies is centered on the treatment of cancer-related cachexia. For this reason, the following paragraphs will summarize the state of the art in terms of therapeutic strategies proposed to counteract this specific form of body wasting.

While is obvious, although not precisely an easy task, that the best treatment for cancer cachexia would be tumor eradication, to reverse or at least delay cachexia should be one of the main goals of therapeutic protocols. Indeed, the occurrence of such syndrome markedly worsens patients' quality of life, increases morbidity and mortality, and reduces the tolerance to antiblastic treatments (Fallowfield, 2002).

\section{Nutritional interventions}

The maintenance of a good nutritional status in cancer patients is a main goal. Indeed, wellnourished patients will recover and will tolerate the side-effects of antineoplastic treatments better than malnourished ones (Ross et al., 2004).

Anorexia is the most effectively treatable cachexia-contributing factor (Laviano et al., 2003). In this regard, different orexigenic drugs have been proposed (Laviano et al., 2005), among which megestrol acetate is the most widely used, although it improves appetite, but not global quality of life (Lopez et al., 2004). A comparable effect was shown for corticosteroids, that also control pain and reduce nausea and asthenia (Loprinzi et al., 1999), likely in view of their ability to inhibit the release of anorexia-inducing cytokines (Patra and Arora, 2012). More recenlty, dronabinol and other cannabinoids were proposed to stimulate appetite (Fide et al., 2005), through both a direct action on the endocannabinoid receptors, and an indirect one on anorexigenic cytokines (Klein et al., 2000; Fide et al., 2005). Finally, gastric cell-derived ghrelin was shown to improve appetite and 
also to interfere with insulin/IGF-1 dependent pathways (see above); of interest, only anorexic cancer patients benefit from ghrelin administration (Neary et al., 2004).

However, anorexia is just one of the factors contributing to the nutritional status of cancer patients. On this line, several tools (fortified normal food, sip food, integrators, nutritional supplements, enteral or parenteral nutrition) aimed at supplementing patients' normal diet are actually available (Rivadaneira et al., 1998). Nutritional supports generally include functional compounds, such as $\omega-3$ polyunsaturated fatty acids (PUFAs; eicosapentenoic and docohesaexaenoic acids), also endowed with anti-inflammatory properties, antioxidants, and aminoacids. In this regard, the branched-chain amino acids (BCAA) leucine, isoleucine and valine, were shown to exert clinically relevant metabolic effects (Bianchi et al., 2005). BCAA administration to cancer patients is reported to result in improved anorexia and energy intake, likely in view of their ability to modulate the synthesis of serotonin in the hypothalamus (Cangiano et al., 1996).

Finally, few years ago, an interesting 'nutritional modulation' approach, based on a rationale somewhat opposite to those described above, and for this reason not easily acceptable by the clinician community, was proposed by Raffaghello and coworkers $(2008,2010)$. In order to counteract the side-effects of chemotherapeutic treatments, the authors proposed to face the metabolic stress occurring after chemotherapy administration by 'preparing' the organism with few days of complete starvation (1-2 days before chemotherapy assumption, 1-2 days after). The study reports that cancer patients voluntary undergoing starvation refer a marked reduction of sideeffects such as fatigue, weakness, nausea, vomiting, diarrhea (Raffaghello et al., 2010). In addition, the same group in a recent report shows that starvation renders tumor cells more prone to the cytotoxic effects of chemotherapeutic drugs and that fasting cycles result in delayed tumor growth (Lee et al., 2012). The approach proposed would thus result in improved effectiveness of antiblastic treatments in face of reduced whole-body toxicity. On this line such a strategy, although not directly aimed at counteracting cachexia, could reveal helpful also in this regard, since chemotherapy toxicity is now recognized to worsen body wasting in cancer patients (Prado et al., 2011). 


\section{Anti-inflammatory strategies}

The interference with the chronic inflammation associated with cachexia was developed on different levels: approaches aimed to down-regulate the inflammatory response in a rather unspecific way (corticosteroids, $\omega-3$ PUFAs, cycloxygenase inhibitors, antioxidants), or strategies targeting specific steps of cytokine-dependent signaling (cytokine production, cytokine-receptor interaction).

Among the unspecific approaches, the most relevant is probably the one based on the use of $\omega-3$ PUFAs. Eicosapentenoic (EPA) and docosaexaenoic (DHA) acid, in particular, are endowed with anti-inflammatory properties, being able to reduce the production of proinflammatory cytokines, of molecules deriving from the arachidonic acid cascade (prostaglandins and leukotrienes), and of acute phase reactants such as CRP (Laviano et al., 2005; Muscaritoli et al., 2006). Tumor-bearing animals treated with EPA show improved body and skeletal muscle weight loss and reduced muscle proteasome enzymatic activity. Of interest, EPA treatment also results in impaired tumor growth and metastasis (Tisdale et al., 1991; Kimura and Sumiyoshi, 2005). Most of EPA effects are ascribed to its ability to antagonize the effects of supposed procachectic factors, namely the lipid mobilizing factor and the proteolysis inducing factor (Tisdale, 2008). Consistently, EPA administration to malnourished patients improves body weight loss and reduces urinary PIF levels (Barber and Fearon, 2001). These observations, however, were not confirmed by a multicenter study on pancreatic cancer patients (Fearon et al., 2003), while another report showed that weight gain induced by administration of megestrol acetate is more marked than the one obtained with EPA (Jatoi et al., 2004) Despite these results, a recent systematic review shows the beneficial effects of $\omega-3$ PUFAs supplementation in cancer, surgical oncology, and critical care patients (van der Meij et al., 2011). In particular, $\omega$-3 PUFAs appears to be mainly effective in terms of quality of life, performance status and physical activity in patients with nonsmall cell lung cancer (NSCLC; van der Meij et al., 2012). Finally, EPA-containing nutritional supplements may be useful to increase perioperative lean body mass in patients with head and neck cancer (Weed et al., 2011). 
Another class of compounds endowed with anti-inflammatory properties is represented by statins, drugs widely used to treat hypercholesterolemia because of their ability to inhibit the hydroxy-methyl glutaryl CoA reductase (Ikeda and Shimada, 1999). Despite this putative antiinflammatory effect, however, simvastatin administration to tumor-bearing animals was unable to correct cancer-induced body and tissue wasting (Muscaritoli et al., 2003).

As reported above, specific anti-cytokine strategies may target cytokine synthesis and release or their interaction with cell surface receptors.

\section{$\underline{\text { Inhibition of cytokine production }}$}

Cytokine production can be blocked by destabilizing their mRNA or by directly interfere with their synthesis or release.

Thalidomide, mainly known in the past because of its teratogenicity, affects proinflammatory cytokine mRNA stability (Haslett, 1998), although more recently, a direct effect on the transcritpion factor NF-kB was also proposed (Wilkes, 2006). A number of clinical trials was set up in order to test thalidomide effectiveness in the management of cancer cachexia. Patients with metastatic cancer receiving thalidomide showed improvement of quality of life (Bruera et al., 1999), weight loss (Khan et al., 2003, Gordon et al., 2005), lean body mass and physical functions (Gordon et al., 2005). Finally, a large randomised trial including cachectic cancer patients showed that thalidomide alone is less effective that its combination with other treatments (Mantovani, 2010). More recently an experimental study reported that thalidomide inhibits an E3 ubiquitin ligase complex involved in embryonal development (Ito et al., 2010), leading to hypothesize that thalidomide effectiveness on muscle wasting in cancer hosts could be achieved through inhibition of muscle-specific ubiquitin ligases.

However, in addition to teratogenicity, thalidomide has several side-effects such as deep venous thrombosis and peripheral neuropathy, constipation, vomiting and drowsiness (BNF, 2009). In this regard, a recent report that systematically reviews data on thalidomide treatment in cancer cachexia clearly shows that the data available are still too much scanty to draw any significant conclusion (Reid et al., 2012). 
Several phosphodiesterase inhibitors were proposed in order to inhibit cytokine synthesis in cachexia, among which pentoxifylline. This drug, in the past used as a hemorheological agent, exerts marked anti-inflammatory actions, leading to beneficial effects on cerebral malaria and chronic sarcoidosis (Zabel et al., 1997; Das et al., 2003). More recently, it was proposed as a tool to treat diabetes (Bryson, 2008). By contrast, data regarding the use of pentoxifylline to treat cachexia are quite conflicting. Its administration to tumor-bearing animals prevents muscle atrophy, mainly by inhibiting the induction of protein hypercatabolism (Combaret et al., 1999; Costelli et al., 2002). On the other side, a double-blind, placebo-controlled study showed that pentoxifylline administration does not improve anorexia nor induces weight gain (Goldberg et al., 1995).

Atractylenolide I, a compound isolated from largehead atractylodes rhizome, used by Chinese traditional medicine to improve nausea, vomiting and anorexia, was proposed to exert anti-inflammatory effects by inhibiting cytokine production (Li et al., 2007). Few years ago it was evaluated as an anticachectic agent in a randomized pilot study including gastric cancer patients. Both body weight and mid-arm muscle circumference significantly increased with respect to the control group, while circulating IL-1 markedly decreased (Liu et al., 2008). Finally, OHR118, a drug endowed with immunomodulatory and cytoprotective properties, is also able to inhibit the synthesis of pro-inflammatory chemokines and cytokines. On these basis, a pilot clinical trial was designed to assess its usefulness in the management of cancer cachexia. Of the 21 patients enrolled, only 11 completed the 2-week study. The results show significant improvements in appetite and depression scores, as well as in weight gain maintenance (Chasen et al., 2011).

Some pro-inflammatory cytokines are synthesized as inactive precursors. This is well known for both interlukin (IL)-1 and TNF $\alpha$, proteolytically activated by the IL1-converting enzyme (ICE, better known as caspase 1; Thornberry et al., 1992) and the TNF $\alpha$-converting enzyme (TACE, or ADAM17; Moss et al., 1997), respectively. Provided that IL-1 is not the most relevant cytokine in the pathogenesis of cachexia, most of the studies have concentrated on the search for inhibitors to TACE, in order to prevent dangerous increases of TNF $\alpha$ levels. TACE inhibitors, 
however, never passed phase II clinical trials (for review see Murumkar et al. 2010), and despite a couple of them were patented for the treatment of cachexia, no supporting literature is available. Interference with cytokine-receptor interaction

The cytokine-receptor engagement can be disrupted by means of cytokine blocking agents (monoclonal antibodies, soluble receptors) or receptor inactivating molecules (receptor antagonists or anti-receptor antibodies). Both groups include molecules commonly used in the clinical practice to reduce the inflammatory response in chronic pathologies such as rheumatoid arthritis or Crohn disease (anti-TNF $\alpha$ monoclonal antibodies, different formulations of soluble TNF $\alpha$-receptor 1 or 2 , IL-1 $\beta$ receptor antagonist; reviewed in Ghezzi and Cerami, 2005]. The literature reports data about the effectiveness of such treatments in preventing body wasting in chronic inflammatory diseases. As an example, etanercept (chimeric soluble TNF $\alpha$ receptor 2) or infliximab (anti-TNF $\alpha$ monoclonal antibody) were reported to increase body weight and lean body mass in patients with rheumatoid arthritis (Briot et al., 2005). Such observation however, was not confirmed by a different study (Marcora et al., 2006). Only few data are actually available about the effectiveness of such kind of drugs in preventing or delaying cancer cachexia. In this regard, anti-TNF $\alpha$ antibodies, while not an antagonist of IL-1 receptor, proved effective in reducing anorexia, body weight loss and protein hypercatabolism in tumor-bearing rats (Costelli et al., 1993; Costelli et al., 1995). More recently, a clinical trial performed on advanced cancer patients receiving etanercept showed the lack of any significant improvement of weight loss, anorexia and survival rate (Jatoi et al., 2007). Another clinical trial shows that lean body mass, performance status, quality of life, progression-free and overall survival, are not different between pancreatic cancer patients receiving gemcitabine alone or gemcitabine plus infliximab (Kishimoto, 1996).

Other compounds are actually reaching the clinical experimentation. In this regard, an antiIL-6 antibody resulted in increased hemoglobinemia and albuminemia in a small phase I trial including patients with advanced cancer. CRP levels also tended to reduction, while an apparent improvement of hand grip strength and fatigue was reported (Clarke et al., 2009). These preliminary results were confirmed by a phase II trial including non small cell lung cancer patients 
receiving the anti-IL-6 antibody at different doses (Bayliss et al., 2011). An anti-IL-6 receptor antibody is also available (Ohtori et al., 2012), however no data are shown in the literature about its effectiveness in both experimental and human cancer cachexia. By contrast, another inhibitor of the interaction betweeen IL-6 and its receptor, 20S,21-epoxy-resibufogenin-3 acetate, appears to prevent carcass weight loss in tumor-bearing mice (Enomoto et al., 2004).

\section{Strategies to correct metabolic alterations}

Derangements of both protein and lipid metabolism play a crucial role in cachexia, since they are directly responsible for the profound tissue wasting that ultimately leads patient to death. In this regard, strategies aimed at targeting such alterations, irrespective of the trigger(s) reponsible for their occurrence (cytokines, anorexia, oxidative stress), are actively pursued.

As for the skeletal muscle, the data collected in the last decade point to deregulation of signaling pathways such as those dependent on insulin/IGF-1, MAP-kinases(p38, JNK, and ERK) and AMP-kinase as crucial in the onset of the protein hypercatabolic response. The insulin/IGF-1dependent signaling, in particular, impinges on both the anabolic and the catabolic side of protein turnover (see above). In this regard, induction of this pathway would result in inhibition of protein breakdown and stimulation of protein synthesis, likely restoring the normal protein content in the wasted muscle. Such a strategy appears to work perfectly well in several experimental models of muscle wasting including denervation, amyotrophic lateral sclerosis, disuse (reviewed in Glass, 2010). However, it is useless in experimental cancer cachexia, where, despite high protein breadown rates occur, the insulin/IGF-1 pathway is not down-regulated, protein synthesis rates are only slightly reduced or even unchanged, and the protein synthetic signaling is poised into the activated state (Costelli et al., 1993; Penna, Bonetto, et al., 2010; Aversa et al., 2012).

Increased activation of the MAPKs was reported in different conditions presenting with muscle wasting, including aging, diabetes and inflammatory myopathies (reviewed in Glass, 2010). In particular, p38 phosphorylation was shown to induce the expression of the ubiquitin ligases atrogin-1 and MuRF1, both in vitro and in vivo (Li et al., 2005; Romanello et al., 2010; Liu et al., 
2011). Activation of p38 was also shown to occur in response to mechanical or electrical stimulation, and functional overload of the skeletal muscle (Boppart et al., 2001; Huey, 2006; Sakamoto et al., 2003), suggesting that this kinase plays a role in both anabolic and catabolic responses. Among the targets of p38 is MAPK-kinase 2 (MKK2). Its phosphorylation at T317 allows MKK2 nuclear export in a complex containing p38 itself (Meng et al., 2002). Phosphorylation of heat shock protein 27 (HSP27), a substrate of MKK2, is increased in skeletal muscle hypertrophy and decreased during atrophy (Huey, 2006; Kawano et al., 2007), while HSP27 hyperexpression reduces disuse-induced muscle depletion (Dodd et al., 2009). Finally, MKK2 expression is reduced also in denervation-induced atrophy (Norrby and Tagerud, 2010). The occurrence of a cross-talk between MKK2/p38 and PI3K/Akt/mTor pathways was proposed. In this regard, the MKK2/p38 complex exported from the nucleus appears to interact with a cytoplasmic HSP27/Akt complex (Wu et al., 2007). Similarly to Akt, also MKK2 impinges on both protein synthesis and catabolism, by phosphorylating molecules involved in the two pathways (reviewed in Rosner et al., 2008). However, despite p38 appears involved in the pathogenesis of muscle wasting, no studies demonstrate that its pharmacological inhibition may result in muscle mass preservation. Preliminary data show that tumor-bearing mice treated with the p38 inhibitor SB203580 are not significantly different from untreated animals in terms of muscle force, food intake and tumor mass (Penna et al., 2012).

The other MAPK possibly involved in modulating muscle protein content is ERK, although its role is still quite controversial. Its inactivation in experimental animals results in muscle atrophy (Shi et al., 2009). Not only, it appears able to counteract the anabolic stimuli induced by treatment with $\beta_{2}$-adrenergic agonists or IGF-1 (Haddad \& Adams, 2004; Shi et al., 2007). Consistently, reduced levels of active ERK were reported in sarcopenia of aging (Carlson et al., 2009). ERK inhibition seems required to increase ubiquitin ligase expression in cultured murine myocytes (Shi et al., 2008). By contrast, in the same model system, ERK activation results in reduced myotube size (Rommel et al., 1999), while its inhibition leads to a hypertrophic phenotype (Rommel et al., 1999). Also the IGF-1 protective effects against oxidative-stress myotube damage would involve 
ERK activity (Yang et al., 2010). Finally, muscle atrophy due to immobilization by hind-limb suspension was associated with increased levels of phosphorylated ERK (Kato et al., 2002). As IGF-1, also ERK plays a role in myogenesis, being able to enhance the regenerative capacity of human satellite cells isolated from both young and old subjects (Carlson et al., 2009). Treatment of mice bearing the C26 colon carcinoma with the ERK inhibitor PD98059 partially but significantly protects tumor hosts from the onset of body weight loss and muscle mass depletion (Penna et al., 2010). ERK inhibition also results in normalization of atrogin-1 hyperexpression, independently from the state of activation of Akt. In addition, Pax7 expression, a marker of activated satellite cells, is significantly increased in the muscle of C26 hosts with respect to controls, while myogenin levels, indicative of an ongoing differentiative process, are reduced. Such a pattern likely reflects an impairment of muscle regeneration, suggesting that the accumulation of activated satellite cells in the muscle of tumor hosts may derive from enhanced proliferation, impaired differentiation, or both. However, when tumor bearers are treated with PD98059, Pax7 and myogenin expression is restored to control values. These observations suggest that ERK activation likely plays a role in maintaining satellite cells in an undifferentiated state, thus contributing with an additional mechanism to muscle depletion (Penna et al., 2010).

Finally, AMPK, that mainly works as a sensor of intracellular energetic balance, is also involved in the regulation of protein turnover (Mihaylova \& Shaw, 2011). AMPK may affect protein synthesis mainly in view of its ability to inhibit mTOR-dependent signaling (Mihaylova \& Shaw, 2011), however it was also shown to modulate protein degradation rates, acting on atrogin-1 expression through a FoxO-dependent mechanism (Nakashima et al., 2007; Romanello et al., 2010). Of interest, increased AMPK activation is detectable in the skeletal muscle of tumor-bearing animals (Penna, Bonetto et al., 2010; White et al., 2011), where it is associated with marked alterations of mitochondrial morphology (Penna et al., unpublished observations).

As a conclusion, protein turnover modulations in the skeletal muscle could also be counteracted by tools aimed at directly inhibiting the intracellular proteolytic systems. In this regard, however, despite encouraging initial observations obtained by treating tumor-bearing animals with 
inhibitor of lysosomal proteases (Ruff and Secrist, 1984; Tessitore et al., 1994), no significant data were obtained.

Proteasome inhibitors (bortezomib), currently used for the treatment of some hematologic malignancies have severe side-effects, and preliminary data show that they are ineffective in preventing muscle wasting in tumor-bearing rats ( $\mathrm{P}$. Costelli and M. Muscaritoli, unpublished data). Similar observations were obtained by treating tumor-bearing animals with inhibitors of the $\mathrm{Ca}^{2+}$ dependent proteolytic system (dantrolene; P. Costelli and M. Muscaritoli, unpublished data) or with an inhibitor of serine proteases (gabexate mesilate; M. Muscaritoli, unpublished observations). The possible explanation for such negative results is that when inhibiting a specific proteolytic system, the others likely compensate, eventually resulting in a pattern of muscle wasting. Not only, a note of care should be introduced in view of administering inhibitors of the lysosomal proteolysis to cachectic subjects. Indeed, tumor-bearing mice with advanced cachexia cannot cope a treatment with bafilomycin, suggesting that the autophagic flux blocked by the inhibitor represents a survival mechanism (Penna et al., unpublished data).

While strategies aimed at blocking muscle protein breakdown are extensively studied, little is done in terms of correction of the altered lipid metabolism. This likely arises from the notion that skeletal muscle mass is the limiting factor for patient survival (see above). This concept, however, should be promptly revised, in view of the results showing that inhibition of lipolytic enzymes in tumor-bearing mice reverses the loss muscle mass, in addition to restoring normal adipose depots (Das et al., 2011; see above).

Little results are avialble in the literature about the use of inhibitors of lipolysis. Recently, YC-1, used as an agent against platelet aggregation, was shown to stimulate preadipocyte differentiation, to inhibit TNF $\alpha$-induced lipolysis in vitro, and to restore normal circulating level of free fatty acids in tumor-bearing mice (Chung et al., 2011). 


\section{Conclusions}

The different options proposed to treat cachexia were built up taking into account the results obtained from experimental and clinical studies, showing that this syndrome is characterized by marked metabolic alterations, mainly due to mediators of both tumor or host origin. In addition, such metabolic perturbations are now recognized to occur very early in the course of the disease, well before any evidence of general wasting. A number of drugs selected because of their effectiveness in preventing experimental cachexia, mostly the cancer-related one, are in the pre-clinical phase, or are presently reaching the clinical experimentation. Of particular relevance, in this regard, appears the adoption of anti-cytokine strategies, although the results available point to combination protocols as the best choice to address the different aspects of cachexia (for example, both lipid and protein mass depletion). Moreover, since cachexia often becomes clinically evident at a rather advanced disease stage, the detection of early subclinical perturbations that may be indicative of a situation of 'latent cachexia' (pre-cachexia) is important in order to prevent the onset of overt cachexia. The definition of effective therapeutic strategies will also reveal useful to improve patients' management and quality of life.

\section{References}

Acharyya, S., Butchbach, M.E., Sahenk, Z., Wang, H., Saji, M., Carathers, M., Ringel, M.D., Skipworth, R.J., Fearon, K.C., Hollingsworth, M.A., Muscarella, P., Burghes, A.H., Rafael-Fortney, J.A., Guttridge, D.C. (2005). Dystrophin glycoprotein complex dysfunction: a regulatory link between muscular dystrophy and cancer cachexia. Cancer Cell. 8, 421-432.

Agustsson, T., Rydén, M., Hoffstedt, J., van Harmelen, V., Dicker, A., Laurencikiene, J., Isaksson, B., Permert, J., Arner, P. (2007). Mechanism of increased lipolysis in cancer cachexia. Cancer Res. 67, 5531-5537. 
Argilés, J.M., López-Soriano, J., Almendro, V., Busquets, S., López-Soriano, F.J. (2005). Crosstalk between skeletal muscle and adipose tissue: a link with obesity? Med. Res. Rev. 25, 49-65.

Attard-Montaldo, S.P., Camacho-Hubner, C., Cotteril, A.M., D’Souza-Li, L., Bartlett, K., Halliday, D., Eden, O.B. (1998). Changes in protein turnover, IGF-I and IGF binding proteins in children with cancer. Acta Pediatr. 87, 54-60.

Aversa, Z., Bonetto, A., Penna, F., Costelli, P., Di Rienzo, G., Lacitignola, A., Baccino, F.M., Ziparo, V., Mercantini, P., Rossi Fanelli, F., Muscaritoli, M. (2012). Changes in Myostatin Signaling in Non-Weight-Losing Cancer Patients. Ann. Surg. Oncol. 19, 1350-1356.

Barber, M.D. and Fearon, K.C. (2001). Tolerance and incorporation of a high-dose eicosapentaenoic acid diester emulsion by patients with pancreatic cancer cachexia. Lipids 36 , 347-351.

Bayliss, T.J., Smith, J.T., Schuster, M., Dragnev, K.H., Rigas, J.R. (2011). A humanized anti-IL-6 antibody (ALD518) in non-small cell lung cancer. Expert Opin. Biol. Ther. 11, 1663-1668.

Beck, S.A., Smith, K.L., Tisdale, M.J. (1991). Anticachectic and antitumor effect of eicosapentaenoic acid and its effect on protein turnover. Cancer Res. 51, 6089-6093.

Bianchi, G., Marzocchi, R., Agostini, F., Marchesini, G. (2005). Update on nutritional supplementation with branched-chain amino acids. Curr. Opin. Clin. Nutr. Metab. Care 8, 83-87.

Bing, C. (2011). Lipid mobilization in cachexia: mechanisms and mediators. Curr. Opin. Support. Palliat. Care 5, 356-360. 
Bonetto, A., Penna, F., Minero, V.G., Reffo, P., Bonelli, G., Baccino, F.M., Costelli, P. (2009).

Deacetylase inhibitors modulate the myostatin/follistatin axis without improving cachexia in tumorbearing mice. Curr. Cancer Drug Targets 9, 608-616.

Bonetto, A., Aydogdu, T., Kunzevitzky, N., Guttridge, D.C., Khuri, S., Koniaris, L.G., Zimmers, T.A. (2011). STAT3 activation in skeletal muscle links muscle wasting and the acute phase response in cancer cachexia. PLoS One 6, e22538.

Boppart, M.D., Hirshman, M.F., Sakamoto, K., Fielding, R.A., Goodyear, L.J. (2001). Static stretch increases c-Jun NH2-terminal kinase activity and p38 phosphorylation in rat skeletal muscle. Am. J. Physiol. Cell. Physiol. 280, C352-C358.

Briot, K., Garnero, P., Le Henanff, A., Dougados, M., Roux, C. (2005). Body weight, body composition, and bone turnover changes in patients with spondyloarthropathy receiving antitumour necrosis factor \{alpha\} treatment. Ann. Rheum. Dis. 64, 1137-1140.

British National Formulary. Vol. 58, London: British Medical Association, September 2009.

Bruera, E., Neumann, C.M., Pituskin, E., Calder, K., Ball, G., Hanson, J. (1999). Thalidomide in patients with cachexia due to terminal cancer: preliminary report. Ann. Oncol. 10, 857-859.

Bruun, J.M., Linn, A.S., Verdich, C., Pedersen, S.B., Toubro, S., Astrup, A., Richelsen, B. (2003). Regulation of adiponectin by adipose tissue-derived cytokines: in vivo and in vitro investigations in humans. Am. J. Physiol. Endocrinol. Metab. 285, E527-E533.

Bryson, N. (2008). Combination for treatment of diabetes mellitus. WO2008151415. 
Cangiano, C., Laviano, A., Meguid, M.M. (1996). Effects of administration of oral branched-chain amino acids on anorexia and caloric intake in cancer patients. J. Natl. Cancer Inst. 88, 550-552.

Carlson, M.E., Suetta, C., Conboy, M.J., Aagaard, P., Mackey, A., Kjaer, M., Conboy, I. (2009). Molecular aging and rejuvenation of human muscle stem cells. EMBO Mol. Med. 1, 381-391.

Chasen, M., Hirschman, S.Z., Bhargava, R. (2011). Phase II study of the novel peptide-nucleic acid OHR118 in the management of cancer-related anorexia/cachexia. J. Am. Med. Dir. Assoc. 12, $62-67$.

Chen, S.E., Gerken, E., Zhang, Y., Zhan, M., Mohan, R.K., Li, A.S., Reid, M.B., Li, Y.P. (2005). Role of TNF-\{alpha\} signaling in regeneration of cardiotoxin-injured muscle. Am. J. Physiol. Cell Physiol. 289, C1179-1187.

Chung, T.H., Yen-Ping Kuo, M., Chen, J.K., Huang, D.M. (2011). YC-1 rescues cancer cachexia by affecting lipolysis and adipogenesis. Int. J. Cancer 9, 2274-2283.

Clarke, S., Gebbie, C., Sweeney, C., Olzewski, N., Smith, J. (2009). A phase I, pharmacokinetic (PK) and preliminary efficacy assessment of ALD518, a humanized anti-IL-6 antibody, in patients with advanced cancer. $5^{\text {th }}$ Cachexia Conference, Barcelona 5-8 December 2009. Abstracts p.53.

Coletti, D., Yang, E., Marazzi, G., Sassoon, D. (2002). TNFalpha inhibits skeletal myogenesis through a PW1-dependent pathway by recruitment of caspase pathways. EMBO J., 21, 631-642.

Coletti, D., Moresi, V., Adamo, S., Molinaro, M., Sassoon, D. (2005). Tumor necrosis factor-alpha gene transfer induces cachexia and inhibits muscle regeneration. Genesis 43, 120-128. 
Combaret, L., Ralliere, C., Taillandier, D., Tanaka, K., Attaix, D. (1999). Manipulation of the ubiquitin-proteasome pathway in cachexia: pentoxifylline suppresses the activation of $20 S$ and 265 proteasomes in muscles from tumor-bearing rats. Mol. Biol. Rep. 26, 95-101.

Costelli, P., Carbó, N., Tessitore, L., Bagby, G.J., Lopez-Soriano, F.J., Argilès,

J.M., Baccino, F.M. (1993). Tumour necrosis factor- $\alpha$ mediates changes in tissue protein turnover in a rat cancer cachexia model. J. Clin. Invest. 92, 2783-2789.

Costelli, P., Llovera, M., Carbó, N. García-Martínez, C., López-Soriano, F.J., Argilés, J.M. (1995). Interleukin-1 receptor antagonist (IL-1ra) is unable to reverse cachexia in rats bearing an ascites hepatoma (Yoshida AH-130). Cancer Lett. 95, 33-38.

Costelli, P., Bossola, M., Muscaritoli, M., Grieco, G., Bonelli, G., Bellantone, R., Doglietto, G.B., Baccino, F.M., Rossi Fanelli F. (2002). Anticytokine treatment prevents the increase in the activity of ATP-ubiquitin- and $\mathrm{Ca2}^{+}$-dependent proteolytic systems in the muscle of tumor-bearing rats. Cytokine. 19, 1-5.

Costelli, P., Muscaritoli, M., Bossola, M., Penna, F., Reffo, P., Bonetto, A., Busquets, S., Bonelli, G., Lopez-Soriano, F.J., Doglietto, G.B., Argilés, J.M., Baccino, F.M., Rossi Fanelli, F. (2006). IGF1 is downregulated in experimental cancer cachexia. Am. J. Physiol. Regul. Integr. Comp. Physiol. 291, R674-R683.

Das, B.K., Mishra, S., Padhi, P.K., Manish, R., Tripathy, R., Sahoo, P.K., Ravindran, B. (2003). Pentoxifylline adjunct improves prognosis of human cerebral malaria in adults. Trop. Med. Int. Health 8, 680-684. 
Das, S.K., Eder, S., Schauer, S., Diwoky, C., Temmel, H., Guertl, B., Gorkiewicz, G., Tamilarasan, K.P., Kumari, P., Trauner, M., Zimmermann, R., Vesely, P., Haemmerle, G., Zechner, R., Hoefler, G. (2011). Adipose triglyceride lipase contributes to cancer-associated cachexia. Science 333, 233-238.

de Heredia, F.P., Gómez-Martínez, S., Marcos, A. (2012). Obesity, inflammation and the immune system. Proc. Nutr. Soc. 20, 1-7.

Dodd, S.L., Hain, B., Senf, S.M., Judge, A.R. (2009). Hsp27 inhibits IKKbeta-induced NF-kappaB activity and skeletal muscle atrophy. FASEB J. 23, 3415-3423.

Durham, W.J., Dillon, E.L., Sheffield-Moore, M. (2009). Inflammatory burden and amino acid metabolism in cancer cachexia. Curr. Opin. Clin. Nutr. Metab. Care 12, 72-77.

Enomoto, A., Rho, M.C., Fukami, A., Hiraku, O., Komiyama, K., Hayashi, M. (2004). Suppression of cancer cachexia by 20S,21-epoxy-resibufogenin-3-acetate-a novel nonpeptide IL-6 receptor antagonist. Biochem. Biophys. Res. Commun. 323, 1096-1102.

Evans, W.J., Morley, J.E., Argilès, J., Bales, C., Baracos, V., Guttridge, D., Jatoi, A., KalantarZadeh, K., Lochs, H., Mantovani, G., Marks, D., Mitch, W.E., Muscaritoli, M., Najand, A., Ponikowski, P., Rossi Fanelli, F., Schambelan, M., Schols, A., Schuster, M., Thomas, D., Wolfe, R., Anker, S.D. (2008). Cachexia: a new definition. Clin. Nutr. 27, 793-799.

Fallowfield, L. (2002). Quality of life: a new perspective for cancer patients. Nat. Rev. Cancer 2, 873-879. 
Fearon, K.C., von Meyenfeldt, M.F., Moses, A.G., Van Geenen, R., Roy, A., Gouma, D.J., Giacosa, A., Van Gossum, A., Bauer, J., Barber, M.D., Aaronson, N.K., Voss, A.C., Tisdale, M.J. (2003). Effect of a protein and energy dense N-3 fatty acid enriched oral supplement on loss of weight and lean tissue in cancer cachexia: a randomised double blind trial. Gut 52,1479-1486.

Fearon, K.C., Voss, A.C., Hustead, D.S. (2006). Cancer Cachexia Study Group. Definition of cancer cachexia: effect of weight loss, reduced food intake, and systemic inflammation on functional status and prognosis. Am. J. Clin. Nutr. 83, 1345-1350.

Fearon, K., Strasser, F., Anker, S.D., Bosaeus, I., Bruera, E., Fainsinger, R.L., Jatoi, A., Loprinzi, C., MacDonald, N., Mantovani, G., Davis, M., Muscaritoli, M., Ottery, F., Radbruch, L., Ravasco, P., Walsh, D., Wilcock, A., Kaasa, S., Baracos, V.E. (2011). Definition and classification of cancer cachexia: an international consensus. Lancet Oncol. 12, 489-495.

Fide, E., Bregman, T., Kirkham, T.C. (2005). Endocannabinoids and food intake: newborn suckling and appetite regulation in adulthood. Exp. Biol. Med. 230, 225-234.

Ghezzi, P. and Cerami, A. (2005). Tumor necrosis factor as a pharmacological target. Mol. Biotechnol. 31, 239-244.

Glass, D.J. (2010). Signaling pathways perturbing muscle mass. Curr. Opin. Clin. Nutr. Metab. Care 13, 225-229.

Goldberg, R.M., Loprinzi, C.L., Mailliard, J.A., O'Fallon, J.R., Krook, J.E., Ghosh, C., Hestorff, R.D., Chong, S.F., Reuter, N.F., Shanahan, T.G. (1995). Pentoxifylline for treatment of cancer anorexia and cachexia? A randomized, double-blind, placebo-controlled trial. J. Clin. Oncol. 13, 2856-2859. 
Gordon, J.N., Trebble, T.M., Ellis, R.D., Duncan, H.D., Johns, T., Goggin, P.M. (2005).

Thalidomide in the treatment of cancer cachexia: a randomised placebo controlled trial. Gut 54, 540-545.

Grossberg, A.J., Scarlett, J.M., Marks, D.L. (2010). Hypothalamic mechanisms in cachexia. Physiol. Behav. 100, 478-489.

Gulen, S.T., Karadag, F., Karul, A.B., Kilicarslan, N., Ceylan, E., Kuman, N.K., Cildag, O. (2012). Adipokines and Systemic Inflammation in Weight-Losing Lung Cancer Patients. Lung DOI 10.1007/s00408-011-9364-6.

Guttridge, D.C., Mayo, M.W., Madrid, L.V., Wang, C.Y., Baldwin, A.S. Jr. (2000). NFkappaBinduced loss of MyoD messenger RNA: possible role in muscle decay and cachexia. Science 289, 2363-2366.

Haddad, F., and Adams, G.R. (2004). Inhibition of MAP/ERK kinase prevents IGF-I-induced hypertrophy in rat muscles. J. Appl. Physiol. 96, 203-210.

Haslett, P.A. (1998). Anticytokine approaches to the treatment of anorexia and cachexia. Semin. Oncol. 25, 53-57.

Huey, K.A. (2006). Regulation of HSP25 expression and phosphorylation in functionally overloaded rat plantaris and soleus muscles. J. Appl. Physiol. 100, 451- 456.

Kadowaki, M., and Kanazawa, T. (2003). Amino acids as regulators of proteolysis. J. Nutr. 133, 2052S-2056S. 
Kato, K., Ito, H., Kamei, K., Iwamoto, I., Inaguma, Y. (2002). Innervation-dependent phosphorylation and accumulation of alphaB-crystallin and Hsp27 as insoluble complexes in disused muscle. FASEB J.16, 1432-1434.

Kawano, F., Matsuoka, Y., Oke, Y., Higo, Y., Terada, M., Wang, X.D., Nakai, N., Fukuda, H., Imajoh-Ohmi, S., Ohira, Y. (2007). Role(s) of nucleoli and phosphorylation of ribosomal protein S6 and/or HSP27 in the regulation of muscle mass. Am. J. Physiol. Cell Physiol. 293, C35-C44.

Kerem, M., Ferahkose, Z., Yilmaz, U.T., Pasaoglu, H., Ofluoglu, E., Bedirli, A., Salman, B., Sahin, T.T., Akin, M. (2008). Adipokines and ghrelin in gastric cancer cachexia. World J. Gastroenterol. $14,3633-3641$.

Khan, Z.H., Simpson, E.J., Cole, A.T., Holt, M., MacDonald, I., Pye, D., Austin, A., Freeman, J.G. (2003). Oesophageal cancer and cachexia: the effect of short-term treatment with thalidomide on weight loss and lean body mass. Aliment. Pharmacol. Ther. 17, 677-682.

Kimura, Y., and Sumiyoshi, M. (2005). Antitumor and antimetastatic actions of eicosapentaenoic acid ethylester and its by-products formed during accelerated stability testing. Cancer Sci. 96, 441450.

Kishimoto, C. (1996). Chugai Pharmaceutical Co LTD. Therapeutic agent for disease due to IL-6 production. JP8169846.

Klein, T.W., Lane, B., Newton, C.A., Friedman, H. (2000). The cannabinoid system and cytokine network. Proc. Soc. Exp. Biol. Med. 225, 1-8. 
Körber, J., Pricelius, S., Heidrich, M., Müller, M.J. (1999). Increased lipid utilization in weight losing and weight stable cancer patients with normal body weight. Eur. J. Clin. Nutr. 53, 740-745.

Ikeda, U., and Shimada, K. (1999). Statins and monocytes. Lancet 353, 2070.

Ito, T., Ando, H., Suzuki, T., Ogura, T., Hotta, K., Imamura, Y., Yamaguchi, Y., Handa, H. (2010). Identification of a primary target of thalidomide teratogenicity. Science $327,1345-1350$.

Jatoi, A., Rowland, K., Loprinzi, C.L., Sloan, J.A., Dakhil, S.R., MacDonald, N., Gagnon, B., Novotny, P.J., Mailliard, J.A., Bushey, T.I., Nair, S., Christensen, B.; North Central Cancer Treatment Group. An eicosapentaenoic acid supplement versus megestrol acetate versus both for patients with cancer-associated wasting: a North Central Cancer Treatment Group and National Cancer Institute of Canada collaborative effort. J. Clin. Oncol. 22, 2469-2476.

Jatoi, A., Dakhil, S.R., Nguyen, P.L., Sloan, J.A., Kugler, J.W., Rowland, K.M. Jr, Soori, G.S., Wender, D.B., Fitch, T.R., Novotny, P.J., Loprinzi, C.L. (2007). A placebo-controlled double blind trial of etanercept for the cancer anorexia/weight loss syndrome: results from N00C1 from the North Central Cancer Treatment Group. Cancer 110, 1396-1403.

Lago, F., Dieguez, C., Gómez-Reino, J., Gualillo, O. (2007). The emerging role of adipokines as mediators of inflammation and immune responses. Cytokine Growth Factor Rev. 18, 313-325.

Lai, K.-M., Gonzalez, M., Poueymirou, W.T., Kline, W.O., Na, E., Zlotchenko, E., Stitt, T.N., Economides, A.N., Yancopoulos, G.D., Glass, D.J. (2004). Conditional activation of akt in adult skeletal muscle induces rapid hypertrophy. Mol. Cell. Biol. 24, 9295-9304.

Laurencikiene, J., Stenson, B.M., Arvidsson Nordström, E., Agustsson, T., Langin, D., Isaksson, B., Permert, J., Rydén, M., Arner, P. (2008). Evidence for an important role of CIDEA in human cancer cachexia. Cancer Res. 68, 9247-9254. 
Laviano, A., Meguid, M.M., Rossi-Fanelli, F. (2003a). Cancer anorexia: clinical implications, pathogenesis, and therapeutic strategies. Lancet Oncol. 4, 686-694.

Laviano, A., Meguid, M.M., Rossi Fanelli, F. (2003b). Improving food intake in anorectic cancer patients. Curr. Opin. Clin. Nutr. Metab. Care 6, 421-426.

Laviano, A., Meguid, M.M., Inui, A., Muscaritoli, M., Rossi Fanelli, F. (2005). Therapy insight: Cancer anorexia-cachexia syndrome--when all you can eat is yourself. Nat. Clin. Pract. Oncol. 2, 158-165.

Lee, C., Raffaghello, L., Brandhorst, S., Safdie, F.M., Bianchi, G., Martin-Montalvo, A., Pistoia, V., Wei, M., Hwang, S., Merlino, A., Emionite, L., de Cabo, R., Longo, V.D. (2012). Fasting cycles retard growth of tumors and sensitize a range of cancer cell types to chemotherapy. Sci. Transl. Med. 4, 124 ra27.

Li, H.H., Willis, M.S., Lockyer, P., Miller, N., McDonough, H., Glass, D.J., Patterson, C. (2007). Atrogin-1 inhibits Akt-dependent cardiac hypertrophy in mice via ubiquitin-dependent coactivation of Forkhead proteins. J. Clin. Invest. 117, 3211-3223.

Li, Y.P., Chen, Y., John, J., Moylan, J., Jin, B., Mann, D.L., Reid, M.B. (2005). TNF- $\alpha$ acts via p38 MAPK to stimulate expression of the ubiquitin ligase atrogin1/MAFbx in skeletal muscle. FASEB J. $19,362-370$.

Li, J.P., Lu, L., Wang, L.J., Zhang, F.R., Shen, W.F. (2011). Increased serum levels of S100B are related to the severity of cardiac dysfunction, renal insufficiency and major cardiac events in patients with chronic heart failure. Clin. Biochem. 44, 984-988. 
Liu, Y., Jia, Z., Dong, L., Wang, R., Qiu, G. (2008). A Randomized Pilot Study of Atractylenolide I on Gastric Cancer Cachexia Patients. Evid. Based Complement Alternat. Med. 5, 337-344.

Liu, Q., Xu, W.G., Luo, Y., Han, F.F., Yao, X.H., Yang, T.Y., Zhang, Y., Pi, W.F., Guo, X.J. (2011). Cigarette smoke-induced skeletal muscle atrophy is associated with up-regulation of USP-19 via p38 and ERK MAPKs. J. Cell. Biochem. 112, 2307-2316.

Lopez, A.P., Roque Figuls, M., Cuchi, G.U., Berenstein, E.G., Pasies, B.A.,Alegre, M.B., Herdman, M. (2004). Systematic review of megestrol acetate in the treatment of anorexia-cachexia syndrome. J.Pain Sympt. Manag. 27, 360-369.

López-Soriano, J., Carbó, N., Tessitore, L., López-Soriano, F.J., Argilés, J.M. (1999). Leptin and tumor growth in rats. Int. J. Cancer. 81, 726-729.

Loprinzi, C.L., Kruger, J.W., Sloan, J.A. (1999). Randomized comparison of megestrol acetate versus dexamethasone versus fluoxymesterone for the treatment of cancer anorexia/cachexia. J. Clin. Oncol. 17, 3299-3306.

Mantovani, G., Macciò, A., Madeddu, C., Serpe, R., Massa, E., Dessì, M., Panzone, F., Contu, P. (2010). Randomized phase III clinical trial of five different arms of treatment in 332 patients with cancer cachexia. Oncologist 15, 200-211.

Marcora, S.M., Chester, K.R., Mittal, G., Lemmey, A.B., Maddison, P.J. (2006).Randomized phase 2 trial of anti-tumor necrosis factor therapy for cachexia in patients with early rheumatoid arthritis. Am. J. Clin. Nutr. 84, 1463-1472. 
Martín, A.I., Castillero, E., Granado, M., López-Menduiña, M., Villanúa, M.A., López-Calderón, A. (2008). Adipose tissue loss in adjuvant arthritis is associated with a decrease in lipogenesis, but not with an increase in lipolysis. J. Endocrinol. 197, 111-119.

Matthys, P., Heremans, H., Opdenakker, G., Billiau, A. (1991). Anti-interferon-gamma antibody treatment, growth of Lewis lung tumours in mice and tumour-associated cachexia. Eur. J. Cancer. $27,182-187$.

Meng, W., Swenson, L.L., Fitzgibbon, M.J., Hayakawa, K., Ter Haar, E., Behrens, A.E., Fulghum, J.R., Lippke, J.A. (2002). Structure of mitogen-activated protein kinase-activated protein (MAPKAP) kinase 2 suggests a bifunctional switch that couples kinase activation with nuclear export. J. Biol. Chem. 277, 37401-37405.

Mihaylova, M.M., Shaw, R.J. (2011). The AMPK signalling pathway coordinates cell growth, autophagy and metabolism. Nat. Cell Biol. 13, 1016-1023.

Moresi, V., Pristera, A., Scicchitano, B.M., Molinaro, M., Teodori, L., Sassoon, D, Adamo, S., Coletti, D. (2008). Tumor necrosis factor-alpha inhibition of skeletal muscle regeneration is mediated by a caspase-dependent stem cell response. Stem Cells 26, 997-1008.

Moss, M.L., Jin, S.L., Milla, M.E., Bickett. D.M., Burkhart, W., Carter, H.L., Chen, W.J., Clay, W.C., Didsbury, J.R., Hassler, D., Hoffman, C.R., Kost, T.A., Lambert, M.H., Leesnitzer, M.A., McCauley, P., McGeehan, G., Mitchell, J., Moyer, M., Pahel, G., Rocque, W., Overton, L.K., Schoenen, F., Seaton, T., Su, J.L., Becherer, J.D., et al. (1997). Cloning of a disintegrin metalloproteinase that processes precursor tumour-necrosis factor-alpha. Nature 385, 733-736. 
Murumkar, P.R., DasGupta, S., Chandani, S.R., Giridhar, R., Yadav, M.R. (2010). Novel TACE inhibitors in drug discovery: a review of patented compounds. Expert. Opin. Ther. Pat. 20, 31-57.

Muscaritoli, M., Costelli, P., Bossola, M. Grieco, G., Bonelli, G., Bellantone, R., Doglietto, G.B., Rossi-Fanelli, F., Baccino, F.M. (2003). Effects of simvastatin administration in an experimental model of cancer cachexia. Nutrition 19, 936-939.

Muscaritoli, M., Bossola, M., Aversa, Z., Bellantone, R., Rossi Fanelli, F. (2006). Prevention and treatment of cancer cachexia: new insights into an old problem. Eur. J. Cancer 42, 31-41.

Muscaritoli, M., Anker, S.D., Argilés, J., Aversa, Z., Bauer, J.M., Biolo, G., Boirie, Y., Bosaeus, I., Cederholm, T., Costelli, P., Fearon, K.C., Laviano, A., Maggio, M., Rossi Fanelli, F., Schneider, S.M., Schols, A., Sieber, C.C. (2010). Consensus definition of sarcopenia, cachexia and precachexia: joint document elaborated by Special Interest Groups (SIG) "cachexia-anorexia in chronic wasting diseases" and "nutrition in geriatrics". Clin. Nutr. 29, 154-159.

Nakashima, J., Tachibana, M., Ueno, M., Miyajima, A., Baba, S., Murai, M. (1998). Association between tumor necrosis factor in serum and cachexia in patients with prostate cancer. Clin. Cancer Res. 4, 1743-1748.

Nakashima, K., and Yakabe, Y. (2007).AMPK activation stimulates myofibrillar protein degradation and expression of atrophy-related ubiquitin ligases by increasing FOXO transcription factors in C2C12 myotubes. Biosci. Biotechnol. Biochem. 71, 1650-1656.

Nara-Ashizawa, N., Akiyama, Y., Maruyama, K., Tsukada, T., Yamaguchi, K. (2001). Lipolytic and lipoprotein lipase (LPL)-inhibiting activities produced by a human lung cancer cell line responsible for cachexia induction. Anticancer Res. 21, 3381-3387. 
Neary, N.M., Small, C.J., Wren, A.M., Lee, J.L., Druce, M.R., Palmieri, C., Frost, G.S., Ghatei, M.A., Coombes, R.C., Bloom, S.R. (2004). Ghrelin increases energy intake in cancer patients with impaired appetite: acute, randomized, placebo-controlled trial. J. Clin. Endocrinol. Metab. 89, 2832-2836.

Nicolas, N., Marazzi, G., Kelley, K., Sassoon, D. (2005). Embryonic deregulation of muscle stress signaling pathways leads to altered postnatal stem cell behavior and a failure in postnatal muscle growth. Dev. Biol. 281, 171-183.

Nienhuis, H.L., Westra, J., Smit, A.J., Limburg, P.C., Kallenberg, C.G., Bijl, M. (2009). AGE and their receptor RAGE in systemic autoimmune diseases: an inflammation propagating factor contributing to accelerated atherosclerosis. Autoimmunity 42, 302-304.

Niewczas, M.A., Gohda, T., Skupien, J., Smiles, A.M., Walker, W.H., Rosetti, F., Cullere, X., Eckfeldt, J.H., Doria, A., Mayadas, T.N., Warram, J.H., Krolewski, A.S. (2012). Circulating TNF receptors 1 and 2 predict ESRD in type 2 diabetes. J. Am. Soc. Nephrol. 23, 507-515.

Noori, N., Kovesdy, C.P., Dukkipati, R., Feroze, U., Molnar, M.Z., Bross, R., Nissenson, A.R., Kopple, J.D., Norris, K.C., Kalantar-Zadeh, K. (2011). Racial and ethnic differences in mortality of hemodialysis patients: role of dietary and nutritional status and inflammation.

Am. J. Nephrol. 33, 157-167.

Norrby, M., and Tågerud, S. (2010). Mitogen-activated protein kinase-activated protein kinase 2 (MK2) in skeletal muscle atrophy and hypertrophy. J. Cell Physiol. 223, 194-201. 
Ohtori, S., Miyagi, M., Eguchi, Y., Inoue, G., Orita, S., Ochiai, N., Kishida, S., Kuniyoshi, K., Nakamura, J., Aoki, Y., Ishikawa, T., Arai, G., Kamoda, H., Suzuki, M., Takaso, M., Furuya, T., Kubota, G., Sakuma, Y., Oikawa, Y., Toyone, T., Takahashi, K. (2012). Efficacy of epidural administration of anti-interleukin-6 receptor antibody onto spinal nerve for treatment of sciatica. Eur. Spine J. DOI: 10.1007/s00586-012-2183-5.

Palacios, D., Mozzetta, C., Consalvi, S., Caretti, G., Saccone, V., Proserpio, V., Marquez, V.E., Valente, S., Mai, A., Forcales, S.V., Sartorelli, V., Puri, P.L. (2010). TNF/p38 $\alpha /$ polycomb signaling to Pax7 locus in satellite cells links inflammation to the epigenetic control of muscle regeneration. Cell Stem Cell 7, 455-469.

Patra, S.K., and Arora, S. (2012). Integrative role of neuropeptides and cytokines in cancer anorexia-cachexia syndrome. Clin Chim Acta doi:10.1016/j.cca.2011.12.008.

Pedersen, B.K., and Febbraio, M.A. (2008). Muscle as an endocrine organ: focus on musclederived interleukin-6. Physiol. Rev. 88, 1379-1406.

Penna. F., Bonetto, A., Muscaritoli, M., Costamagna, D., Minero. V.G., Bonelli, G., Rossi Fanelli, F., Baccino, F.M., Costelli, P. (2010). Muscle atrophy in experimental cancer cachexia: Is the IGF-1 signaling pathway involved? Int. J. Cancer. 127, 1796-1717.

Penna, F., Costamagna, D., Fanzani, A., Bonelli, G., Baccino, F.M., Costelli, P. (2010). Muscle wasting and impaired myogenesis in tumor bearing mice are prevented by ERK inhibition. PLoS One 5, e13604. 
Penna, F., Costamagna, D., Camperi, A., Muscaritoli, M., Baccino, F.M., Bonelli, G. (2012). Protein kinases in the pathogenesis of muscle wasting. In: "Protein kinases/Book 2" (G. Da Silva Xavier, Ed.), in press. InTech, Rijeka, Croatia.

Pisters, P.W., and Pearlstone, D.B. (1993). Protein and amino acid metabolism in cancer cachexia: investigative techniques and therapeutic interventions. Crit. Rev. Clin. Lab. Sci. 30, 223-272.

Popa, C., Netea, M.G., Radstake, T.R., van Riel, P.L., Barrera, P., van der Meer, J.W. (2005). Markers of inflammation are negatively correlated with serum leptin in rheumatoid arthritis. Ann. Rheum. Dis. 64, 1195-1198.

Prado, C.M., Lieffers, J.R., McCargar, L.J., Reiman, T., Sawyer, M.B., Martin, L., Baracos, V.E. (2008). Prevalence and clinical implications of sarcopenic obesity in patients with solid tumours of the respiratory and gastrointestinal tracts: a population-based study. Lancet Oncol. 9, 629-635.

Prado, C.M., Antoun, S., Sawyer, M.B., Baracos, V.E. (2011). Two faces of drug therapy in cancer: drug-related lean tissue loss and its adverse consequences to survival and toxicity. Curr. Opin. Clin. Nutr. Metab. Care. 14, 250-254.

Prehn, R.T. (1972). The immune reaction as a stimulator of tumor growth. Science 176, 170-171.

Raffaghello, L., Lee, C., Safdie, F.M., Wei, M., Madia, F., Bianchi, G., Longo, V.D. (2008). Starvation-dependent differential stress resistance protects normal but not cancer cells against high-dose chemotherapy. Proc. Natl. Acad. Sci. USA 105, 8215-8220.

Raffaghello, L., Safdie, F., Bianchi, G., Dorff, T., Fontana, L., Longo, V.D. (2010). Fasting and differential chemotherapy protection in patients. Cell Cycle 9, 4474-4476. 
Reid, J., Mills, M., Cantwell, M., Cardwell, C.R., Murray, L.J., Donnelly, M. (2012). Thalidomide for managing cancer cachexia. Cochrane Database Syst. Rev. 18, 4, CD008664.

Rivadaneira, D.E., Evoy, D., Fahey, T.J. $3^{\text {rd }}$, Lieberman, R.D., Daly, J.M. (1998). Nutritional support of the cancer patient. C.A. Cancer J. Clin. 48: 69-80.

Romanello, V., Guadagnin, E., Gomes, L., Roder, I., Sandri, C., Petersen, Y., Milan, G., Masiero, E., Del Piccolo, P., Foretz ,M., Scorrano, L., Rudolf, R., Sandri, M. (2010). Mitochondrial fission and remodelling contributes to muscle atrophy. EMBO J. 29, 1774-1785.

Rommel, C., Clarke, B.A., Zimmermann, S., Nunez, L., Rossman, R., Reid, K., Moelling, K., Yancopoulos, G.D., Glass, D.J. (1999). Differentiation stage-specific inhibition of the Raf-MEKERK pathway by Akt. Science 286, 1738-1741.

Rommel, C., Bodine, S.C., Clarke, B.A., Rossman, R., Nunez, L., Stitt, T.N., Yancopoulos, G.D., and Glass, D.J. (2001). Mediation of IGF-1-induced skeletal myotube hypertrophy by $\mathrm{PI}(3) \mathrm{K} / \mathrm{Akt} / \mathrm{mTOR}$ and PI(3)K/Akt/GSK3 pathways. Nat. Cell Biol. 3, 1009-1013.

Rosner, M., Hanneder, M., Siegel, N., Valli, A., and Hengstschläger, M. (2008). The tuberous sclerosis gene products hamartin and tuberin are multifunctional proteins with a wide spectrum of interacting partners. Mutat. Res. 658, 234-246.

Ross, P.J., Ashley, S., Norton, A., Priest, K., Waters, J.S., Eisen, T., Smith, I.E., O'Brien, M.E. (2004). Do patients with weight loss have a worse outcome when undergoing chemotherapy for lung cancers? Br. J. Cancer. 90, 1905-1911. 
Ruff, R.L., and Secrist, D. (1984). Inhibitors of prostaglandin synthesis or cathepsin B prevent muscle wasting due to sepsis in the rat. J. Clin. Invest. 73, 1483-1486.

Sakamoto, K., Aschenbach, W.G., Hirshman, M.F., Goodyear, L.J. (2003). Akt signaling in skeletal muscle: regulation by exercise and passive stretch. Am. J. Physiol. Endocrinol. Metab. 285, E1081-E1088.

Sakurai, Y., and Klein, S. (1998). Metabolic alterations in patients with cancer: nutritional implications. Surg. Today 28, 247-57.

Sandri, M., Sandri, C., Gilbert, A., Skurk, C., Calabria, E., Picard, A., Walsh, K., Schiaffino, S., Lecker, S.H., Goldberg, A.L. (2004). Foxo transcription factors induce the atrophy-related ubiquitin ligase atrogin-1 and cause skeletal muscle atrophy. Cell 117, 399-412.

Seruga, B., Zhang, H., Bernstein, L.J., Tannock, I.F. (2008). Cytokines and their relationship to the symptoms and outcome of cancer. Nat. Rev. Cancer 8, 887-899.

Shan, X., and Yeo, G.S. (2011). Central leptin and ghrelin signalling: comparing and contrasting their mechanisms of action in the brain. Rev. Endocr. Metab. Disord. 12, 197-209.

Shi, H., Zeng, C., Ricome, A., Hannon, K.M., Grant, A.L., Gerrard, D.E. (2007). Extracellular signal-regulated kinase pathway is differentially involved in beta-agonist-induced hypertrophy in slow and fast muscles. Am. J. Physiol. Cell. Physiol. 292, C1681-C1689.

Shi, H., Scheffler, J.M., Pleitner, J.M., Zeng, C., Park, S., Hannon, K.M., Grant, A.L., Gerrard, D.E. (2008). Modulation of skeletal muscle fiber type by mitogen-activated protein kinase signaling. FASEB J. 22, 2990-3000. 
Shi, H., Scheffler, J.M., Zeng, C., Pleitner, J.M., Hannon, K.M., Grant, A.L., Gerrard, D.E. (2009). Mitogen-activated protein kinase signaling is necessary for the maintenance of skeletal muscle mass. Am. J. Physiol. Cell. Physiol. 296, C1040-C1048.

Späte, U., and Schulze, P.C. (2004). Proinflammatory cytokines and skeletal muscle. Curr. Opin. Clin. Nutr. Metab. Care 7, 265-269.

Stenholm, S., Harris, T.B., Rantanen, T., Visser, M., Kritchevsky, S.B., Ferrucci, L. (2008). Sarcopenic obesity: definition, cause and consequences. Curr. Opin. Clin. Nutr. Metab. Care 11, 693-700.

Stephens, N.A., Skipworth, R.J., Fearon, K.C. (2008). Cachexia, survival and the acute phase response. Curr. Opin. Support. Palliat. Care 2, 267-274.

Stitt, T.N., Drujan, D., Clarke, B.A., Panaro, F., Timofeyva, Y., Kline, W.O., Gonzalez, M., Yancopoulos, G.D., Glass, D.J. (2004). The IGF-1/PI3K/Akt pathway prevents expression of muscle atrophy-induced ubiquitin ligases by inhibiting FOXO transcription factors. Mol. Cell. 14, 395-403.

Strassmann, G., Fong, M., Freter, C.E., Windsor, S., D'Alessandro, F., Nordan, R.P. (1993). Suramin interferes with interleukin-6 receptor binding in vitro and inhibits colon-26-mediated experimental cancer cachexia in vivo. J. Clin. Invest. 92, 2152-2159.

Tan, B.H., and Fearon, K.C. (2008). Cachexia: prevalence and impact in medicine. Curr. Opin. Clin. Nutr. Metab. Care 11, 400-407. 
Tessitore, L., Costelli, P., Baccino, F.M. (1994). Pharmacological interference with tissue protein hypercatabolism in tumor-bearing rats. Biochem. J. 299, 71-78.

Thornberry,NA., Bull, H.G., Calaycay, J.R., Chapman, K.T., Howard, A.D., Kostura, M.J., Miller, D.K., Molineaux, S.M., Weidner, J.R., Aunins, J., et al. (1992). A novel heterodimeric cysteine protease is required for interleukin-1 beta processing in monocytes.

Nature 356, 768-7674.

Tisdale, M.J. (2008). Catabolic mediators of cancer cachexia. Curr. Opin. Support. Palliat. Care 2, 256-261.

Trayhurn, P., and Wood, I.S. (2004). Adipokines: inflammation and the pleiotropic role of white adipose tissue. Br. J. Nutr. 92, 347-355.

van de Woestijne, A.P., Monajemi, H., Kalkhoven, E., Visseren, F.L. (2011). Adipose tissue dysfunction and hypertriglyceridemia: mechanisms and management. Obes. Rev. 12, 829-840.

van der Meij, B.S., van Bokhorst-de van der Schueren, M.A., Langius, J.A., Brouwer, I.A., van Leeuwen, P.A. (2011). n-3 PUFAs in cancer, surgery, and critical care: a systematic review on clinical effects, incorporation, and washout of oral or enteral compared with parenteral supplementation. Am. J. Clin. Nutr. 94, 1248-1265.

Wallace, A.M., Sattar, N., McMillan, D.C. (1998). Effect of weight loss and the inflammatory response on leptin concentrations in gastrointestinal cancer patients. Clin. Cancer Res. 4, 29772979.

Walsh, D., Rybicki, L., Nelson, K.A., Donnelly, S. (2002). Symptoms and prognosis in advanced cancer. Support. Care Cancer 10, 385-388. 
Weed, H.G., Ferguson, M.L., Gaff, R.L., Hustead, D.S., Nelson, J.L., Voss, A.C. (2011). Lean body mass gain in patients with head and neck squamous cell cancer treated perioperatively with a protein- and energy-dense nutritional supplement containing eicosapentaenoic acid. Head Neck 33, 1027-1033.

White, J.P., Baynes, J.W., Welle, S.L., Kostek, M.C., Matesic, L.E., Sato, S., Carson, J.A. (2011). The regulation of skeletal muscle protein turnover during the progression of cancer cachexia in the Apc(Min/+) mouse. PLoS One 6, e24650.

Wilkes, E.A., and Freeman, J.G. (2006). Thalidomide: an effective anabolic agent in gastrointestinal cancer cachexia. Aliment. Pharmacol. Therap. 23, 445-446.

Winfield, R.D., Delano, M.J., Pande, K., Scumpia, P.O., Laface, D., Moldawer, L.L. (2008). Myeloid-derived suppressor cells in cancer cachexia syndrome: a new explanation for an old problem. J. Parenter. Enteral. Nutr. 32, 651-655.

Wolfe, R.R. (2006). The underappreciated role of muscle in health and disease. Am. J. Clin. Nutr. $84,475-482$.

Wu, R., Kausar, H., Johnson, P., Montoya-Durango, D.E., Merchant, M., Rane, M.J. (2007). Hsp27 regulates Akt activation and polymorphonuclear leukocyte apoptosis by scaffolding MK2 to Akt signal complex. J. Biol. Chem. 282, 21598-21608.

Yang, S.Y., Hoy, M., Fuller, B., Sales, K.M., Seifalian, A.M., Winslet, M.C. (2010). Pretreatment with insulin-like growth factor I protects skeletal muscle cells against oxidative damage via PI3K/Akt and ERK1/2 MAPK pathways. Lab. Invest. 90, 391-401. 
Zabel, P., Entzian, P., Dalhoff, K., Schlaak, M. (1997). Pentoxifylline in treatment of sarcoidosis. Am. J. Respir. Crit. Care Med. 155,1665-1669.

Zhao, J., Brault, J.J., Schild, A., Cao, P., Sandri, M., Schiaffino, S., Lecker, S.H., Goldberg, A.L. (2007). FoxO3 coordinately activates protein degradation by the autophagic/lysosomal and proteasomal pathways in atrophying muscle cells. Cell Metab. 6, 472-483. 